\title{
Main Polysaccharides Isolated and Quantified of Aloe vera Gel in Different Seasons of the Year
}

\author{
Berenice Aranda Cuevas ${ }^{1}$, Carlos Hernán Herrera Méndez ${ }^{2 *}$, Ignacio Islas Flores ${ }^{3}$, \\ Sara Solís-Pereira ${ }^{1}$, Luis Cuevas-Glory ${ }^{1}$, Gerardo Rivera Muñoz ${ }^{1}$, \\ María de Lourdes Vargas y Vargas ${ }^{1}$, Jorge Tamayo Cortez ${ }^{1}$ \\ ${ }^{1}$ Research and Postgraduate Division, Instituto Tecnológico de Mérida, Mérida, Mexico \\ ${ }^{2}$ Agroindustrial Engineering Department, Universidad de Guanajuato, Campus Celaya-Salvatierra, \\ Salvatierra, México \\ ${ }^{3}$ Centro de Investigación Científica de Yucatán, Mérida, México \\ Email: *caherhe_23@hotmail.com
}

Received 17 March 2016; accepted 24 May 2016; published 27 May 2016

Copyright (C) 2016 by authors and Scientific Research Publishing Inc.

This work is licensed under the Creative Commons Attribution International License (CC BY). http://creativecommons.org/licenses/by/4.0/

(c) (i) Open Access

\begin{abstract}
We developed and implemented a methodology that allowed extracting and evaluating high molecular weight polysaccharides present in the gel of Aloe barbadensis Miller. One of the fractions evaluated revealed the presence of high molecular weight carbohydrates $(200 \mathrm{kDa})$ with a behavior similar to that of acemannan and another fraction with compounds of molecular weights between 17 and $47 \mathrm{kDa}$. We quantified the concentration of acemannan for two different growing periods. The concentration of acemannan in the high molecular weight fraction was $99.97 \mathrm{ppm}$ in the rainy season and $106.03 \mathrm{ppm}$ in the dry season. The concentration of acemannan in the fraction of low molecular weight was $9.364 \mathrm{ppm}$ during the season of greatest rainfall and $26.939 \mathrm{ppm}$ in the dry season.
\end{abstract}

\section{Keywords}

Acemannan, Aloe vera, Gel, Polysaccharides, Rainy Season, Dry Season

\section{Introduction}

The genus Aloe has four known species with medicinal properties: Aloe barbadensis Miller, Aloe perryi Baker, "Corresponding author. 
Aloe ferox and Aloe arborecens [1] [2]. There is particular interest in studying the species A. barbadensis Miller because it is the most widely cultivated in the world and the one that is more easily managed; it is also known that this species has a more potent medicinal effect. This species is commonly known as Aloe vera [2] [3].

Aloe gel contains a wide composition of polysaccharides, which have been reported as agents that stimulate the immune system. Most have been identified as glucomannan, mannan (acetylated) and pectin, all with different molecular weights [4]. The pharmacological activities of acemannans include antiviral effects, induction of the production of nitric oxide, stimulation of $\mathrm{T}$ cells, and macrophage activation. Some acemannans can exert their therapeutic properties through macrophages [5].

Aloe has attracted interest as a crop due to its adaptability and properties; it requires limited irrigation, depending on the ability of the soil to retain moisture, being a plant species with crassulacean acid metabolism (CAM) adapted to dry conditions and high temperatures. Aloe vera shows variations in the efficiency of water use, biomass production and gel production when subjected to different concentrations of water [6]. In the Yucatan Peninsula, Mexico, there are 1019 hectares of plantations perfectly suited to the soil and climatic conditions of the area. The total production of Aloe vera in the state of Yucatan in 2007 was of 3944.06 tonnes. However, it is necessary to promote the virtues of this plant in order to give it greater added value; thus, in this work we develop and implement a methodology that allows to extract and evaluate high molecular weight polysaccharides present in the gel of Aloe barbadensis Miller, and also perform a characterization of the polysaccharide fractions present in the gel both in conditions of excess and scarcity of water, using acemannan as reference.

\section{Materials and Methods}

\subsection{Reagents and Samples}

Pyridine (Mallinckrodt Baker, Inc., Phillipsburg, NJ, USA); L-Butanol (Mallinckrodt Baker, Inc., Phillipsburg, NJ, USA); Sephacryl S-300-H (Sigma-Aldrich Co., St. Louis, MO); Standard Acemannan from Verapol Premium ${ }^{\circledR}$ (donated by Natural Aloe of Costa Rica S.A., 4 km Liberia-Guanacaste). $\mathrm{H}_{2} \mathrm{SO}_{4}$ (Mallinckrodt Baker, Inc., Phillipsburg, NJ, USA); 3,5-Dinitrosalicylic acid (Sigma Co., St. Louis, MO); Silica gel 60 G (Merck, Street 5, No.7 Industrial Park Alce Blanco, 53370, Mexico).

Freshly cut Aloe vera leaves were obtained from "Sabilerosdel Mayab" plantations located in Yucatan, Mexico. The leaves were harvested in two different seasons, the first in the months of August-September (rainy season) and the second in March-April (dry season), to evaluate the effect of water on the concentration of the polysaccharides.

\subsection{Extraction of Aloe vera Gel}

The leaves of Aloe vera were washed and disinfected in chlorinated water for $20 \mathrm{~min}$ and allowed to dry. Two cross sections of $15 \mathrm{~cm}$ and $5 \mathrm{~cm}$ were performed at the apex and the base respectively, and allowed to drain to remove the bitterness. The side edges were cut to loosen the epidermis on both sides. The fillet obtained was homogenized with a blender to obtain a juice.

\subsection{Determination of Total Sugars}

The composition of total carbohydrates was assessed using a colorimetric assay with phenol red (5\% w/v in water) and concentrated sulfuric acid. The absorbance reading was $490 \mathrm{~nm}$ [7].

\subsection{Determination of Reducing Sugars}

The analysis of reducing sugars was performed following the DNS method [8].

\subsection{Isolation by Ultrafiltration}

One liter of Aloe vera gel was filtered through four layers of gauze and then with Whatmanfilter paper no. 1 to remove coarse solids. The filtrate was passed through a membrane of $0.2 \mu \mathrm{m}$ in order to remove smaller impurities.

Using an ultrafiltration device Amicon ${ }^{\circledR}$ Ultra-0.5 (Millipore, Sigma-Aldrich Co., St. Louis, MO), we ob- 
tained two fractions of $A$. vera gel with a nominal molecular weight limit (NMWL) of $100 \mathrm{kDa}$. One fraction contained components smaller than $100 \mathrm{kDa}$ (concentrate), and the other compounds larger than $100 \mathrm{kDa}$ (filtrate).

\subsection{Molecular Exclusion Chromatography}

The $100 \mathrm{kDa}$ fraction was used to extract polysaccharides by size-exclusion chromatography (SEC). We used a chromatographic column of $95 \mathrm{~cm}$ of height and $1 \mathrm{~cm}$ of diameter, and a Sephacryl S-300 (Sigma-Aldrich Co., St. Louis, MO). The elution was performed with sterile bi-deionized water, and 80 fractions of $1 \mathrm{~mL}$ were collected. We used molecular weight markers (dextran blue) to estimate the size of the polysaccharides contained in the fractions. The 80 fractions were evaluated with thin-layer chromatography (TLC), using n-butanol: pyridine. water as solvent (6:4:3). The development was done with $\mathrm{H}_{2} \mathrm{SO}_{4}$ and $\mathrm{H}_{2} \mathrm{O}$ (2:1), with subsequent heating at $105^{\circ} \mathrm{C}$.

\subsection{Colorimetric Tests for Polysaccharides Present in the Aloe Extract}

To determine the content of polysaccharides in the Aloe extract, we quantified acemannan using a colorimetric assay [9].

\section{Results and Discussion}

Table 1 shows the recovery percentages of polysaccharides obtained by filtration and ultrafiltration. It is noted that for every $100 \mathrm{~g}$ of Aloe vera gel, $4.27 \mathrm{~g}$ of gel with polysaccharides of molecular weight higher than 100 $\mathrm{kDa}$ are obtained.

\subsection{Total Sugars}

Samples of Aloe juice collected during times of drought and rain filtered with filter paper showed values of total sugars of $5.944 \mathrm{mg} / \mathrm{mL}$ and $2.988 \mathrm{mg} / \mathrm{mL}$ respectively, while the values for samples filtered with a $0.22 \mu \mathrm{m}$ membrane were $4.348 \mathrm{mg} / \mathrm{mL}$ and 1,839 $\mathrm{mg} / \mathrm{mL}$, respectively (Figure 1 (a)).

\subsection{Reducing Sugars}

Similarly, it was observed that the content of reducing sugars in samples of Aloe juice collected during the periods evaluated was $2.71 \mathrm{mg} / \mathrm{mL}$ and $1.659 \mathrm{mg} / \mathrm{mL}$ in samples filtered with paper, and $2.695 \mathrm{mg} / \mathrm{mL}$ and 1.437 $\mathrm{mg} / \mathrm{mL}$ in samples filtered with a $0.22 \mu \mathrm{m}$ membrane during times of drought and rain, respectively (Figure $1(\mathrm{~b}))$.

The dry season led to an increase in the concentration of total and reducing sugars in both fractions. Studies found that Aloe vera plants underwent osmotic adjustment due to the increase in total sugars, proline and other components when subjected to different amounts of water [10]. Likewise, previous studies have indicated concluded that the presence of these compounds can vary according to the different stages of growth [11]. It is possible that the increase of sugars is related to the amount of water during the rainy season.

\subsection{Analysis of the Fractions by Thin-Layer Chromatography}

The fractions were analyzed by thin-layer chromatography (TLC): concentrate $(\leq 100 \mathrm{kDa})$ and filtrate $(>100$ $\mathrm{kDa}$ ); we used glucose, galactose, arabinose and acemannan standards (Figure 2). Table 2 shows the retardation

Table 1. Recovery percentages of the extraction of the polysaccharides (P/P).

\begin{tabular}{ccc}
\hline Process & Filtrate (\%) & Retained (\%) \\
Gel Extraction & 22.69 & 77.31 \\
Filter Paper (Whatman No.1) & 22.41 & 0.28 \\
Membrane of $0.22 \mu \mathrm{m}$ & 17.09 & 5.32 \\
Microcon ${ }^{\circledR} 100$ & 12.82 & 4.27 \\
\hline
\end{tabular}


Table 2. Retardation factor (Rf) obtained in Aloe vera.

\begin{tabular}{ccc}
\hline Sample & Rf & SDs. \\
Glucose & 0.475 & 0.006 \\
Galactose & 0.425 & 0.007 \\
Arabinose & 0.5 & 0.006 \\
Acemannan & 0 & 0 \\
Concentrate $(\leq 100 \mathrm{kDa})$ & 0.437 & 0.059 \\
Filtrate $(>100 \mathrm{kDa})$ & 0.437 & 0.0469 \\
\end{tabular}
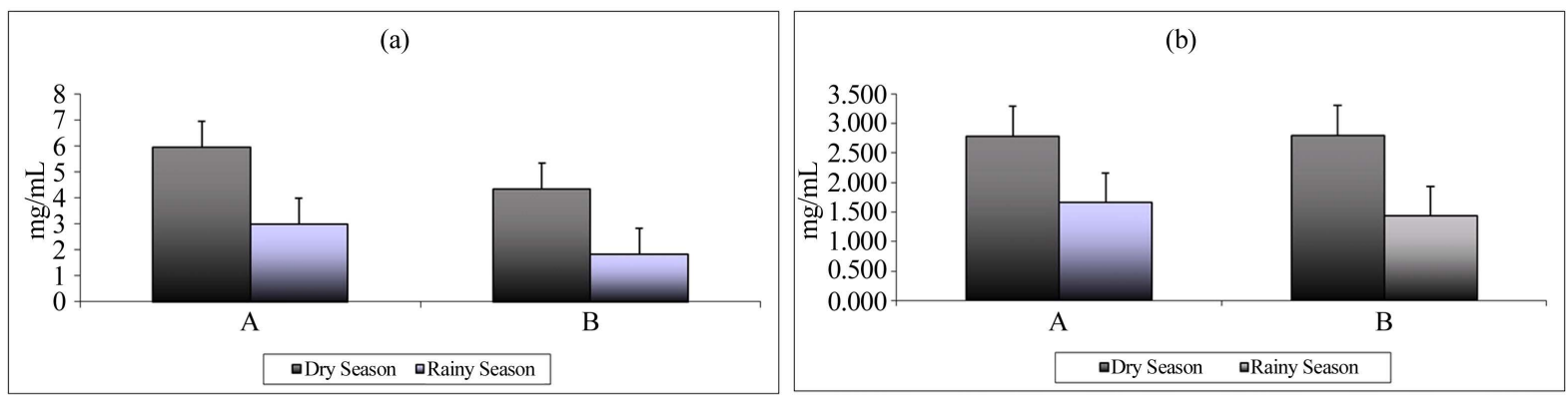

Figure 1. (a) Composition total sugars; (b) Composition of reducing sugars of Aloe vera in the dry and rainy seasons. (A) Filtered with filter paper; (B) Membrane filtration.

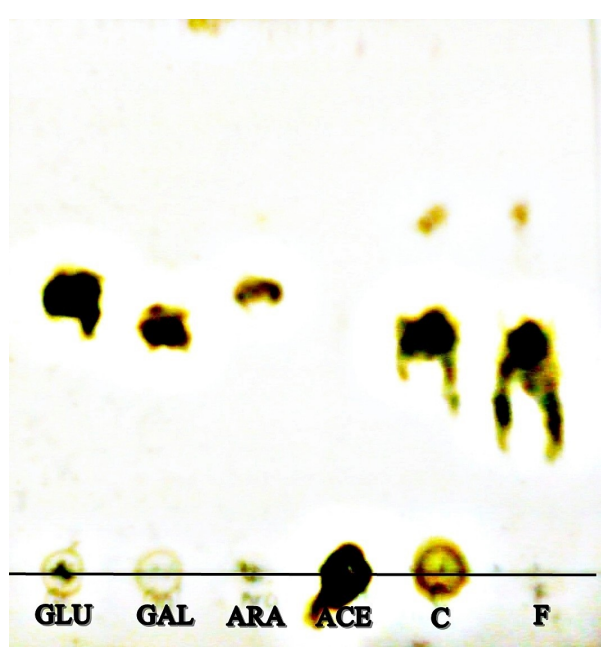

Figure 2. TLC chromatogram of the reference standards and the first 2 fractions of Aloe. GLU: glucose; ARA: Arabinose; GAL: Galactose; ACE: acemannan; C: $\leq 100 \mathrm{kDa}$; F: $>100 \mathrm{kDa}$.

factor (Rf) obtained for each applied sample. The Rf for glucose was $0.475,0.425$ for galactose and 0.5 for arabinose; these values are similar to those reported by previous studies [12]. The acemannan standard was revealed at the application point; two compounds were observed in the concentrate fraction, one at the point of application, and another with an Rf of 0.437 . Two compounds were also observed in the filtrate fraction, one with an Rf of 0.437 and another with an Rf of 0.625 . None of the Rf coincides with the reference patterns, indicating that these are different compounds.

The analysis by TLC of the fractions of the dry season obtained by size exclusion chromatography (SEC) yielded the record of a compound at the origin of fractions 28,30 and 32, and another analysis yielded a fainter record of a compound in fraction 34, all at the application point of the fraction (Figure 3(a)). In the sample of the rainy season, a compound was observed at the origin of fractions 28 to 36 (faint spot) (Figure 3(b)), similar 


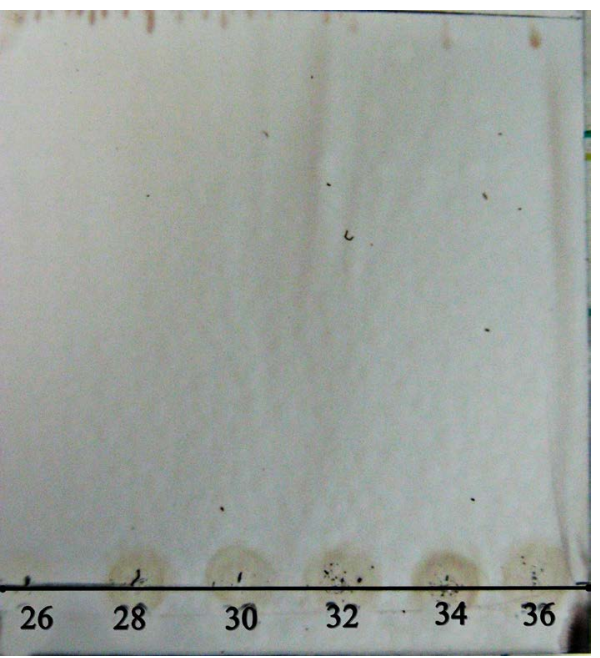

(a)

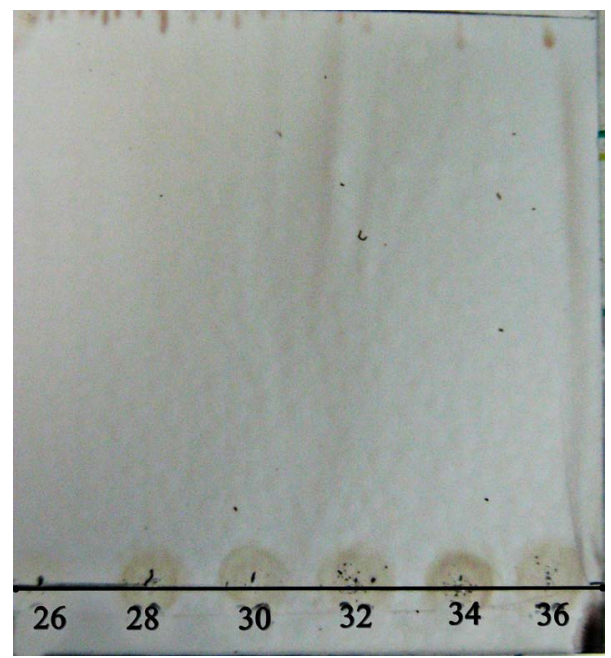

(b)

Figure 3. Chromatogram of the fractions collected from the Sephacryl S-300 column (26, 28, 30, 32, 34, 36). (a) March-April (b) August-September.

to the standard of acemannan in both seasons. Similar results were reported in TLC chromatograms of the mucilaginous polysaccharide Basellaalba Linn, where the compound was found near the origin [13].

The fractions with compounds larger than $200 \mathrm{kDa}$ were grouped together, according to the results (Figure 4). The type and molecular size of the polysaccharides isolated from Aloe gel seem to be very diverse, as described by several authors [14] [15]. The heterogeneity of the molecular weight of the polysaccharides may be due to the techniques used to isolate them, or to their degradation by the activity of the endogenous enzymes [12]. Similarly, previous studies, collected polysaccharides of between 21 and $109 \mathrm{kDa}$ from elutions of 20 to $60 \mathrm{~mL}$ in the neutral separation (distilled water) of carbohydrates present in Aloe arborescens [16].

\subsection{Quantification of Acemannan}

Figure 5 shows the concentration of acemannan in the fractions obtained from the size exclusion column in the two seasons evaluated. The fraction of low molecular weight showed $26.939 \mathrm{ppm}$ and $9.364 \mathrm{ppm}$ of acemannan in the dry and rainy seasons, respectively. As expected, the shortage of rain increased the concentration of acemannan by nearly twice (Figure 5(A)).

In contrast, the high molecular weight fraction showed concentrations of acemannan of $106.03 \mathrm{ppm}$ and 99.97 ppm for the dry and rainy seasons, respectively (Figure 5(B)). The increase in the concentration of acemannan was not significant (6.06\%) during the dry season, indicating that there is a higher concentration of acemannan in the fraction of molecular weight greater than $200 \mathrm{kDa}$, which is consistent with the reports of some authors that the average molecular weight of the native polysaccharides such as acemannan fluctuates around two million daltons or higher [14] [15].

Recent research estimated the presence of acemannan as a phytomarker using the colorimetric method with congo red in commercial formulations of creams containing Aloe vera. The developed spectrophotometric method accurately measured the acemannan sample and it was found that the method was sensitive and accurate for routine analysis of the quality of Aloe vera in cosmetic formulations [17].

\section{Conclusion}

In the present work, we succeeded in developing and implementing a methodology that allowed us to extract and evaluate high molecular weight polysaccharides present in the gel of Aloe barbadensis Miller in times of drought and rain. The dry season led to an increase in the concentration of total and reducing sugars. The evaluated fractions revealed the presence of high weight carbohydrates (larger than $200 \mathrm{kDa}$ ), with characteristics similar to those of acemannan and other compounds of lower molecular weight, between 17 and $47 \mathrm{kDa}$. The concentration of acemannan was quantified in the two fractions obtained by molecular exclusion. The high 


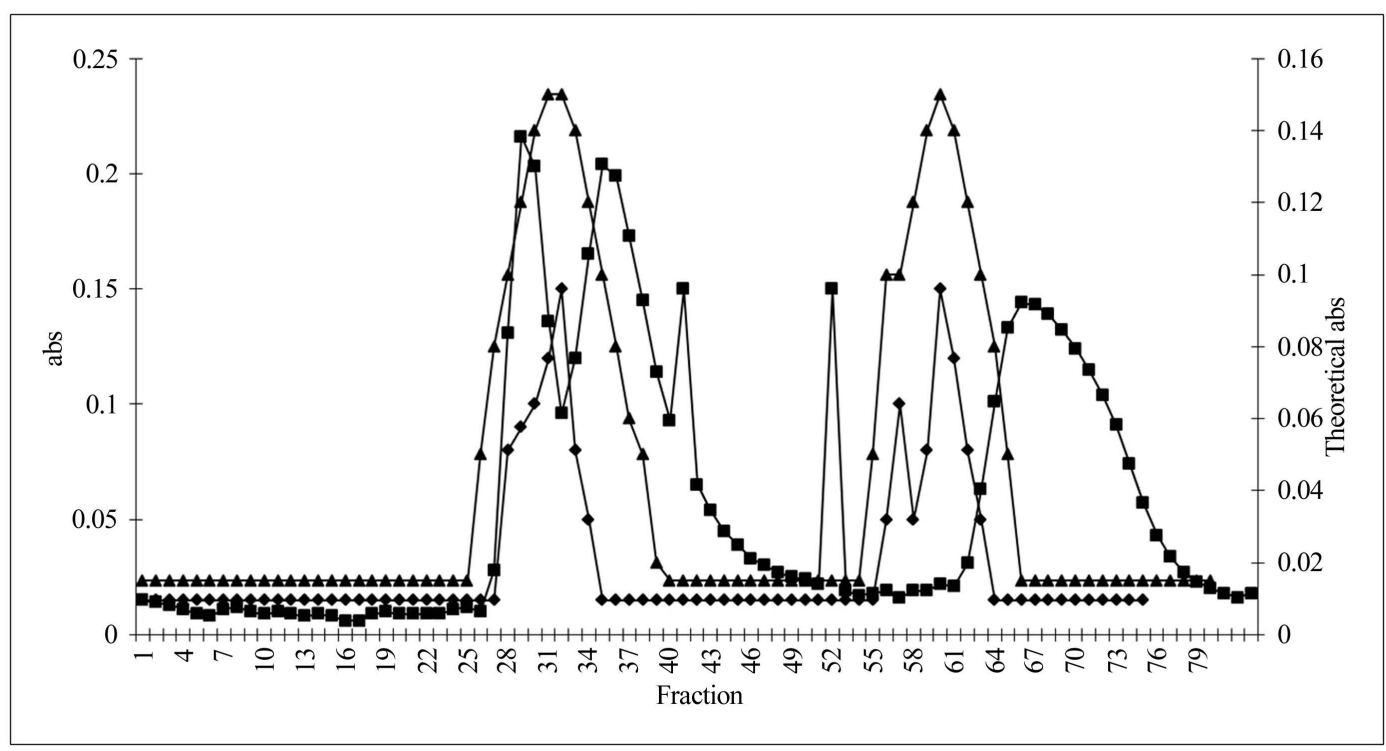

Figure 4. Comparison of Aloe fractions obtained by SEC on a Sephacryl S-300 column (匹 Molecular weight standards; $\bullet$ March-April season; $\boldsymbol{\Delta}$ August-September season).

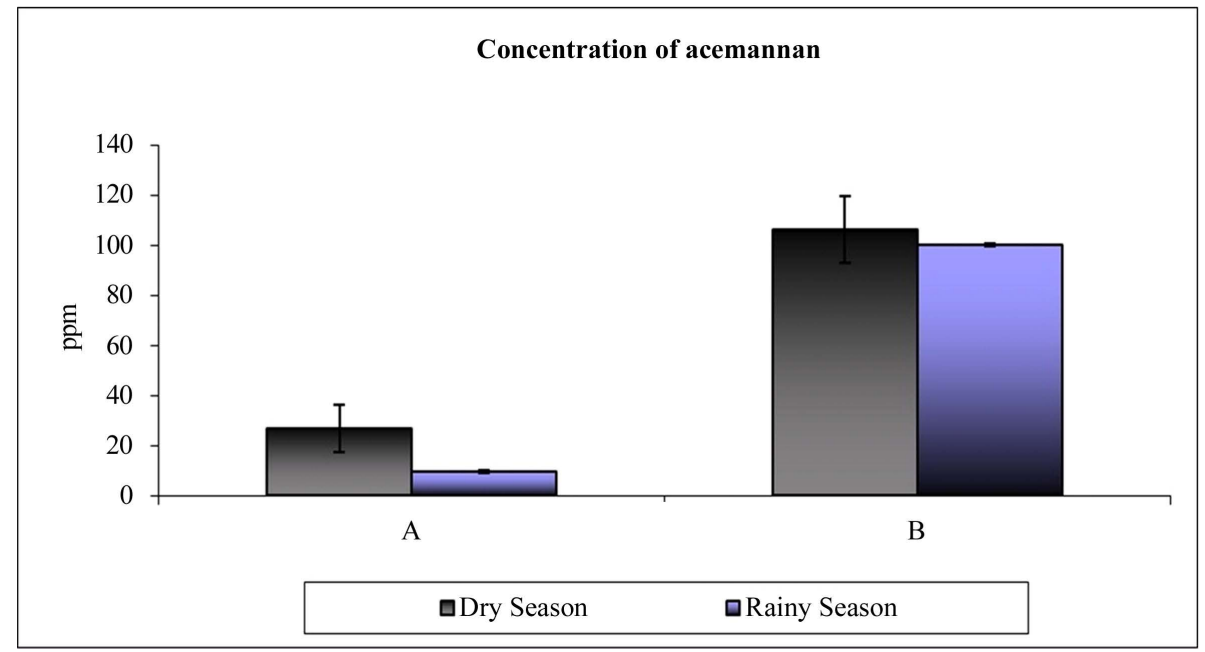

Figure 5. Concentration of acemannan in Aloe vera in the two seasons evaluated. (A) Low Molecular Weight Fraction (B) High Molecular Weight Fraction.

molecular weight fraction showed a higher concentration of this compound in both seasons (99.97 ppm in rainy season and $106.03 \mathrm{ppm}$ in dry season) than the fraction of low molecular weight (9.364 ppm and $26.939 \mathrm{ppm}$ in the rainy and dry seasons, respectively) which confirmed that the average molecular weight of acemannan was high (over two million Daltons) and that the season of drought or rain does not significantly affected the concentration of acemannan.

\section{References}

[1] Jia, Y., Zhao, G. and Jia, J. (2008) Preliminary Evaluation: The Effects of Aloe Ferox Miller and Aloe arborescens Miller on Wound Healing. Journal of Ethnopharmacology, 120, 181-189. http://dx.doi.org/10.1016/j.jep.2008.08.008

[2] Basmatker, G., Jains, N. and Daud, F. (2011) Aloe vera: A Valuable Multifunctional Cosmetic Ingredient. International Journal of Medicinal and Aromatic Plants, 1, 338-341.

[3] Reynolds, T. (2004) Aloes “The genus Aloe”. CRC Press LLC, USA, 408.

[4] Pugh, N., Ross, S.A., ElSohly, M. and Pasco, D.S. (2001) Characterization of Aloe Ride, a New High-Molecular- 
Weight Polysaccharide from Aloe vera with Potent Immunostimulatory Activity. Journal of Agricultural and Food Chemistry, 49, 1030-1034. http://dx.doi.org/10.1021/jf001036d

[5] Aloharrif, M.M. and Sandeep, K.V. (2011) Aloe vera Their Chemicals Composition and Applications: A Review. International Journal of Biological and Medical Research, 9, 466-471.

[6] Silva, H., Sagardia, S., Seguel, O., Torres, C., Tapia, C., Franck, N. and Cardemil, L. (2009) Effect of Water Availability on Growth and Water Use Efficiency for Biomass and Gel Production in Aloe vera (Aloe barbadensis M.). Industrial Crops and Products, 31, 20-27. http://dx.doi.org/10.1016/j.indcrop.2009.08.001

[7] Dubois, M., Gilles, K.A., Hamilton, J.K., Rebers, P.A. and Smith, F. (1956) Colorimetric Method of Determination of Sugars and Related Substances. Analytical Chemistry, 28, 350-356. http://dx.doi.org/10.1021/ac60111a017

[8] Miller, G.L. (1959) Use of Dinitrosalicylic Acid Reagent for Determination of Reducing Sugar. Analytical Chemestry, 31, 426-428. http://dx.doi.org/10.1021/ac60147a030

[9] Eberendu, A.R., Luta, G., Edwards, J.A., McAnalley, B.H., Davis, B., Rodriguez, S. and Henry, C.R. (2005) Quantitative Colorimetric Analysis of Aloe Polysaccharides as a Measure of Aloe vera Quanlity in Commercial Products. Journal of AOAC International, 88, 684-691.

[10] De la Torre, H.J., Delfino, I., Salinas, C., Silva, C. and Liliana, C. (2010) Irrigation Restriction Effects on Water Use Efficiency and Osmotic Adjustment in Aloe vera Plants (Aloe barbadensis Miller). Agricultural Water Management, 97, 1564-1570. http://dx.doi.org/10.1016/j.agwat.2010.05.008

[11] Varindra, P.J., Diviya, J., Joginder, S. and Gosal, S.S. (2011) Biochemical Studies of Aloe vera (Aloe barbadensis Miller) Gel of the Field Grown and Micropropagated Plants at Different Developmental Stages. Journal of Plant Biochemistry and Biotechnology, 20, 283-287. http://dx.doi.org/10.1007/s13562-011-0040-y

[12] Zweig, G. and Sherma, J. (1972) Handbook Chromatography General Data and Principles. Vol. 1, CRC Press, Boca Ratón.

[13] Chuennapa, C., Natsajee, N., Srisomporn, P., Supatra, P. and Aroonsri, P. (2010) Physical and Biological Properties of Mucilage from Basella alba L. Stem and Its Gel Formulation. Iran Journal of Pharmaceutical Sciences, 6, 104-112.

[14] Reynolds, T. and Dweck, A.C. (1999) Aloe vera Gel Leaf: A Review Update. Journal of Ethnopharmacology, 68, 337. http://dx.doi.org/10.1016/S0378-8741(99)00085-9

[15] Im, S.A., Oh, S.T., Song, S., Kim, M.R., Kim, D.S., Woo, S.S., Jo, T.H., Park, Y.I. and Lee, C.K. (2005) Identification of Optimal Molecular Size of Modified Aloe Polysaccharides with Maximum Immunomodulatory. International Immunopharmacology, 5, 271-279. http://dx.doi.org/10.1016/j.intimp.2004.09.031

[16] Chang, X.L., Feng, Y.M. and Wang, W.H. (2011) Comparison of the Polysaccharides Isolated from Skin Juice, Gel Juice and Flower of Aloe arborescens Tissues. Journal of the Taiwan Institute of Chemical Engineers, 42, 13-19. http://dx.doi.org/10.1016/j.jtice.2010.04.008

[17] Prerak, P., Sunil, K., Devang, S., Niyati, A., Vimalkumar, S. and Sanjeev, A. (2012) Exploration of Acemannan as a Phytomarker for Aloe barbadensis Gel and Its Estimation in Different Marketed Cosmeceutical Formulations. Inventi Impact: Cosmeceuticals, 4. 